\title{
Sound and Digital Class Room: Smart Way to have a Language Laboratory
}

\author{
Budi Yulianto, Muhsin Shodiq and Lusiana Citra Dewi
}

Binus University, Jl. K. H. Syahdan No. 9, Palmerah, Jakarta Barat 11480, Indonesia

Received 2013-01-03, Revised 2013-05-23; Accepted 2013-06-01

\begin{abstract}
Development of information technology encourages educational institution to run the multimedia system interactively and easily. Multimedia technology that has video and audio streaming element takes an important role in interactive teaching activities between teachers and students. Streaming or transmission of video and audio has bandwidth, delay and loss packet. The objective is to design and develop an interactive multimedia system for language classroom to facilitate learning activities. The system is connected through LAN network used combination of TCP, UDP and RSTP connection to cover optimal bandwidth, delay and loss packet. The methodology is literature study, observation and system design using Unified Modeling Language (UML) approach. Automated and interactive learning activity using multimedia streaming technology. The system is tested and its main functionality is only focusing on Class Speech, Personal Speech, Share Desktop and Share Video. All these functionality can run very well, but need several improvement for next version.
\end{abstract}

Keywords: Multimedia, Video and Audio Streaming, Language Classroom, TCP, UDP, RSTP, Unified Modeling Language (UML)

\section{INTRODUCTION}

Nowadays, information technology has become an important part of people's daily activities. Information technology can be applied to make people's daily activities and institution's operations a lot easier. Education institutions are also applying information technology to their teaching activities. Multimedia streaming is one of applied technologies that can be used for teaching activities (Sunardi, 2010). It allows teachers to share knowledge to students interactively through computers and networks. Unfortunately, many education institutions must pay a lot to use the system. Not all education institutions can afford to buy it. So, mostly only higher education institution (like universities) has kind of that system.

Video and audio media can make teaching activities more attractive to students. Especially for learning language in a classroom, shown in Fig. 1, with full equipped of Personal Computers (PCs) for Corresponding Author: Budi Yulianto, Binus University, Jl. K. H. Syahdan No. 9, Palmerah, Jakarta Barat 11480, Indonesia

teachers and students. Essential equipments those are needed in a language classroom are networked computers, storage devices, LCD projectors, whiteboards (Eskicioglu and Kopec, 2003). Video and audio can help students to understand easier. The challenges come when the system that streams the video and audio media must be easy to use for teachers and can help teaching activities in that kind of classroom.

State of the art of this research is to design a classroom management that applies multimedia streaming technology for interactive learning in multimedia language classroom (Tayel and Taha 2008). Delivering video and audio over network is an important issue for many multimedia applications. It can cause teaching activities disturbed. Combination of network protocol must be made to optmize multimedia streaming. Hopefully, this technology can make better interaction between teachers and students, runs smooth and can be used in university level and school level. 


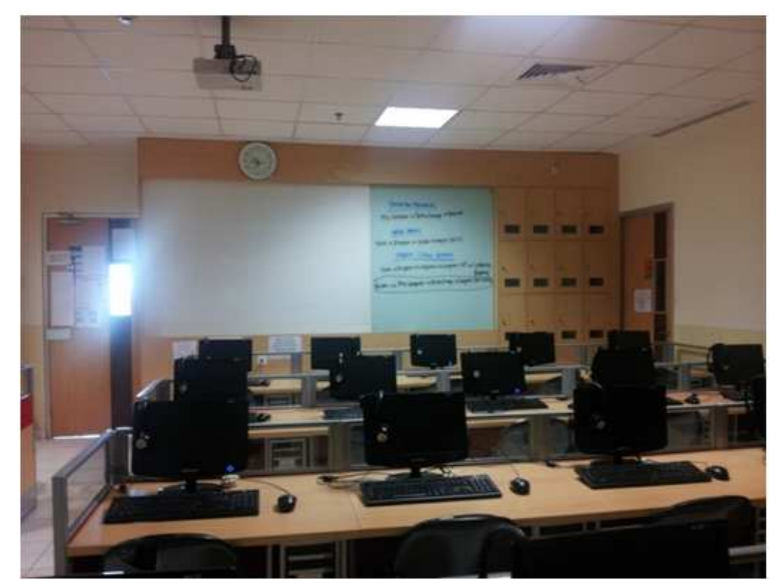

Fig. 1. Classroom for learning language

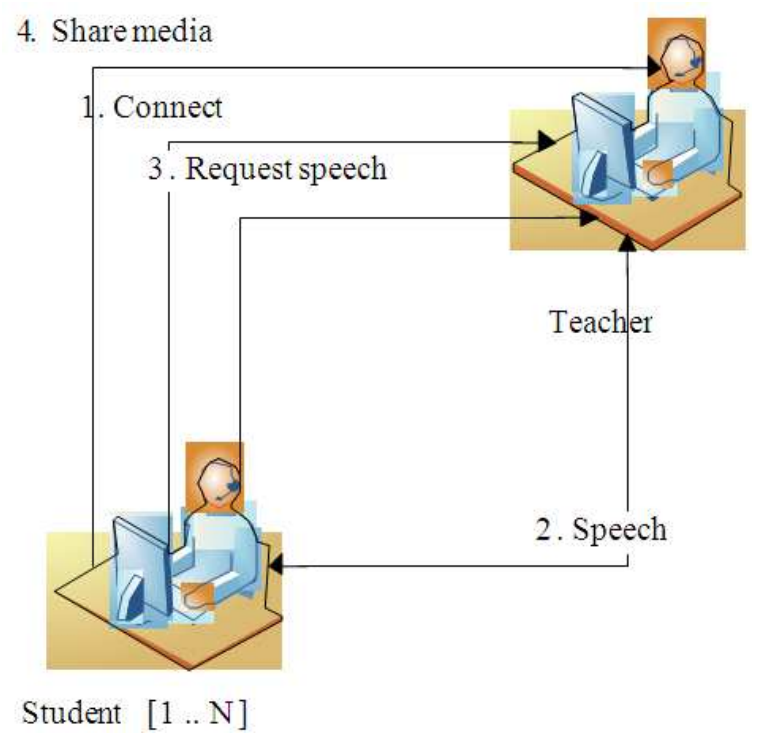

Fig. 2. Rich picture of proposed system

\subsection{Proposed System}

There are 2 actors in the system, Teacher and Student. Generally, Teacher and Student can interact using the system (Fig. 2): (1) Student connects to the Teacher, (2) Teacher and all of Student can communicate, (3) Student can ask for private communication with Teacher and (4) Teacher can share media like video, audio, or even his/her desktop view.

Module design for the system will accommodate all the interactions between Student or group of Students and Teacher. All the modules will be divided into 4 groups of modules which can be developed independently. The 4 groups are Speech modules, Sharing modules, Security modules and Control modules.

Many important activities in the classroom can be done through the application. Process flow of the application that shown on Fig. 3 and 4 are described as follows. Connect activity is used to check whether Teacher's application and Student's application are connected through network or not. After that, next activity can be divided into 3 groups which are Speech activity, Sharing and Security activity and Control activity. These 3 groups can run parallel. Personal Speech activity enables two-way communications between a teacher and a student. Class Speech enables one-way communications from Teacher to all Students. Student Speech activity enables one-way communications from a Student to all Students and a Teacher. Student Speech activity is combined with Class Speech, so that the Teacher can reply immediately to all Students. Group Speech enables Teacher to do a one-way communication to a group of Students. Record Speech enables Teacher to record a Student's voice for checking their competencies in language. Share Desktop enables teacher to share any material that are displayed in his/her monitor to all Students. Share Media enables Teacher to share video or audio media to all students. Share desktop and Share Media activity can be combined with Class Speech activity. So when Teacher shares their material or media, they can also talk to the class. Blank Monitor activity enables Teacher to make all Students' monitor into blank, so all Students' can pay attention to the Teacher in front of the classroom. This activity also includes locking the keyboard and the mouse.

The user interface for this application was designed as simple as possible (Fig. 5-8). The icons used for each button are also made the Teacher and Student easier to remember the functions. This application also provides manual instruction for firsttime user (Fig. 12).

\subsection{System Specification}

The system consists of two applications, one for Teacher and another for Students. The class diagrams documentation are shown on Fig. 9 and 10 and described the relation of classes in Teacher and Student application side. The minimum specification for this system is a few units of standard personal computers equipped with headsets in a classroom. 


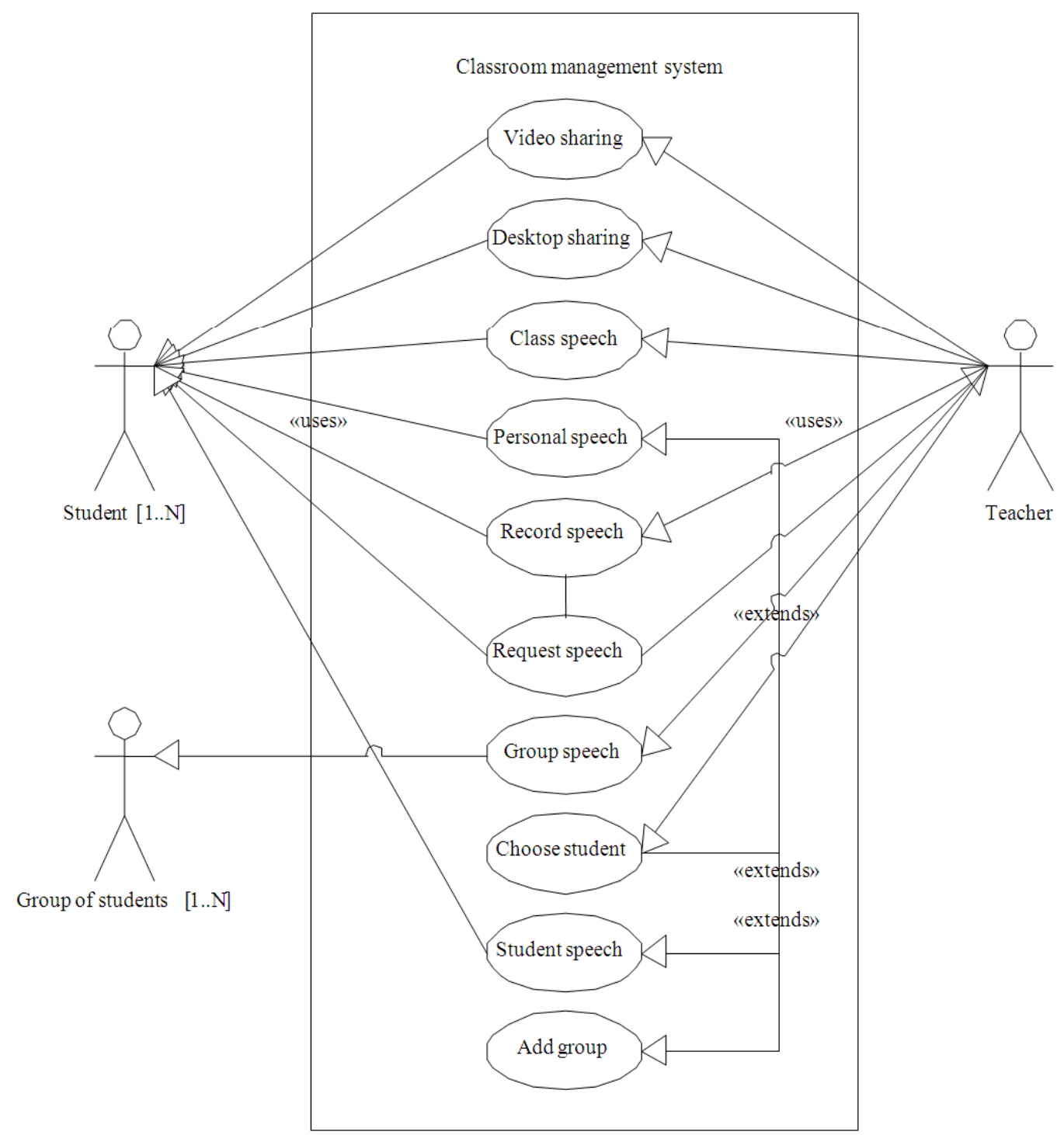

Fig. 3. Use case diagram of the system

Those PCs must be connected through network (no need for internet connection, only LAN is enough). Detailed specifications for PC are:

- Processor: Intel Pentium 4 1.7Ghz

- RAM: 512 MB

- Graphic card memory: $32 \mathrm{MB}$

- Monitor's resolution: $1024 \times 800 \mathrm{p}$

- Headset: All types, with microphone

The great challenge in processing as well as in transmission is multimedia applications that streams video. The appropriate or suitable connections model due to correct behavior of each needs must be applied or combined to achieve optimal works. The connection types that used in the system are Transmission Control Protocol (TCP) connection, User Datagram Protocol (UDP) connection, Real Time Streaming Protocol (RTSP) connection. Connection type that used in the system is shown on Fig. 11. TCP connection used to give command from Teacher's application to Student's application. This connection is very reliable for accurate transferring data (Lee et al., 2010). 
Budi Yulianto et al. / Journal of Computer Science 9 (6): 708-715, 2013

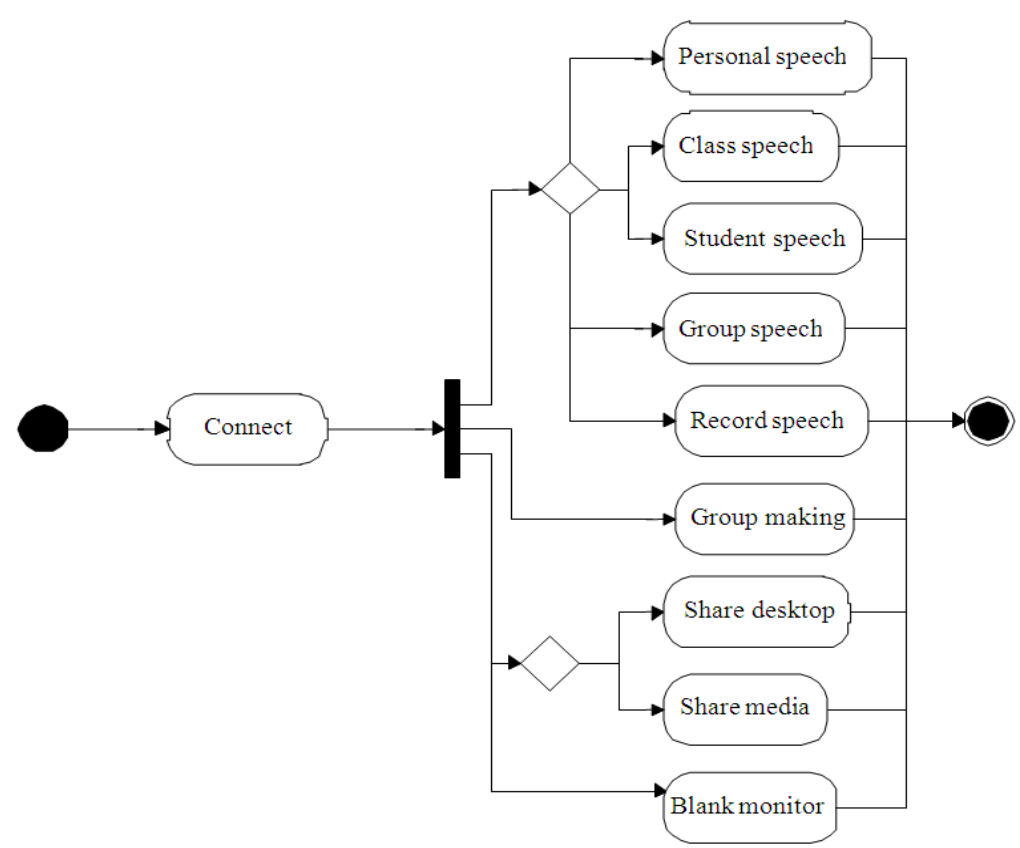

Fig. 4. Activity diagram of the system

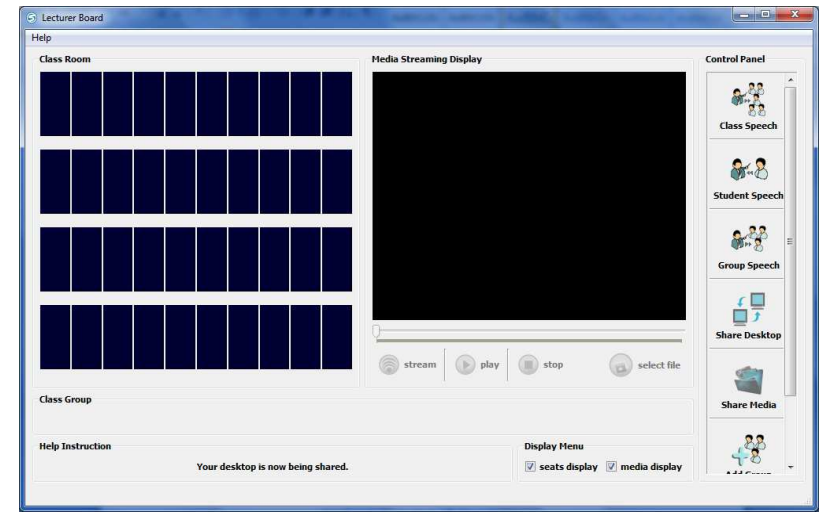

Fig. 5. User interface for teacher application side

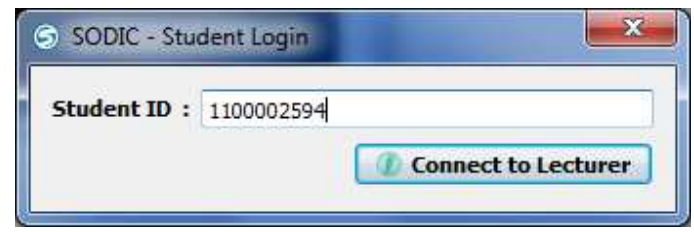

Fig. 6. User interface for student application side (Login Form)

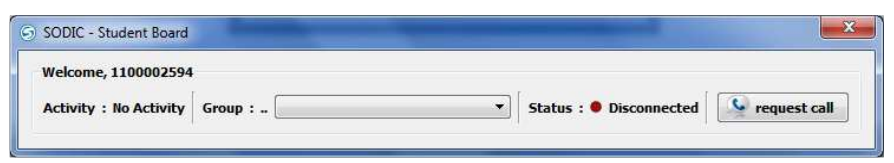

Fig. 7. User interface for student application side (Status Form) 
Budi Yulianto et al. / Journal of Computer Science 9 (6): 708-715, 2013

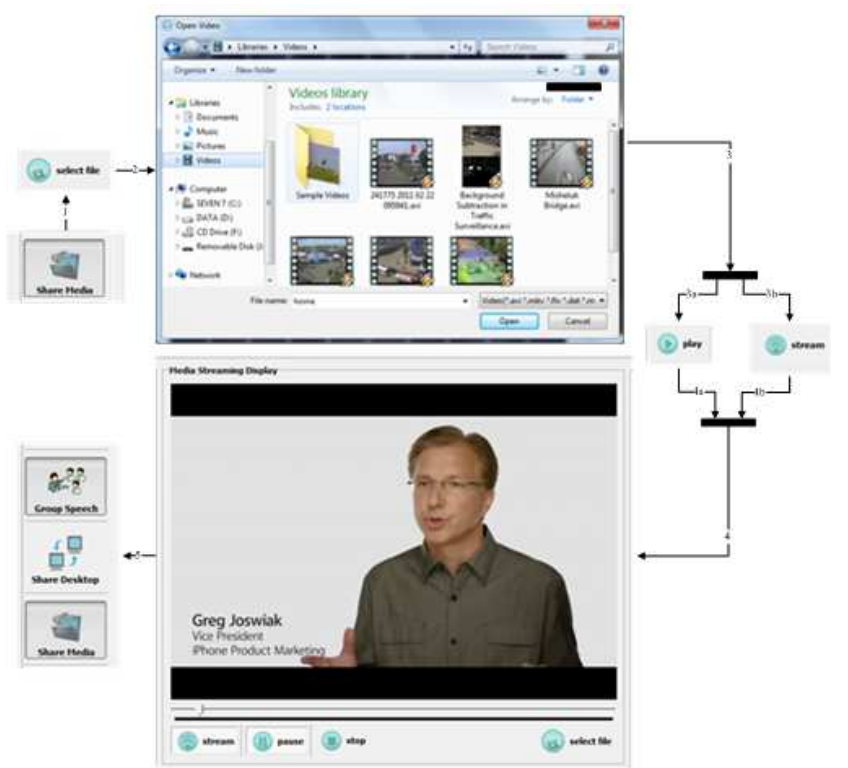

Fig. 8. Share media activity in the application

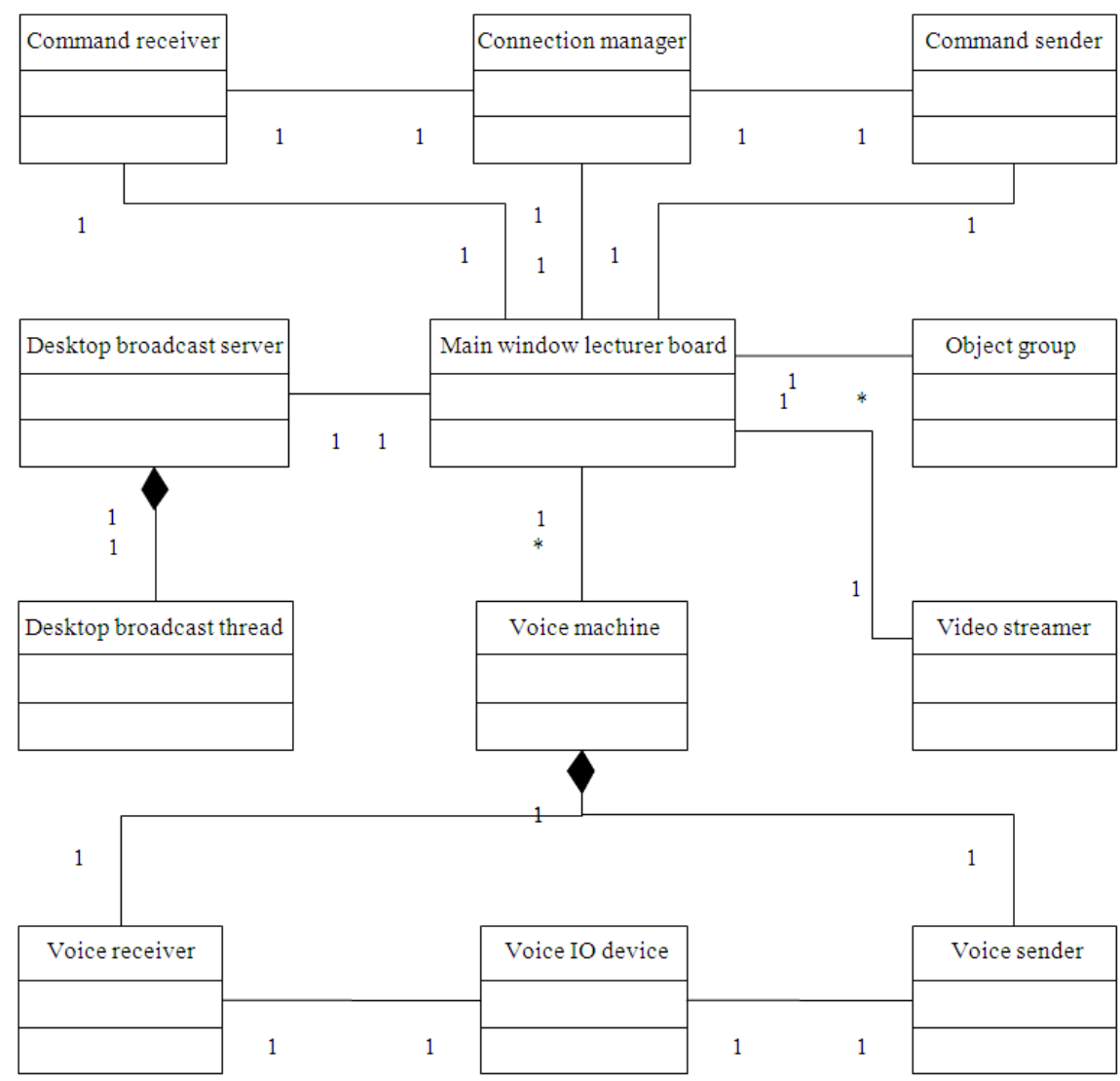

Fig. 9. Class diagram of the system (teacher application side) 


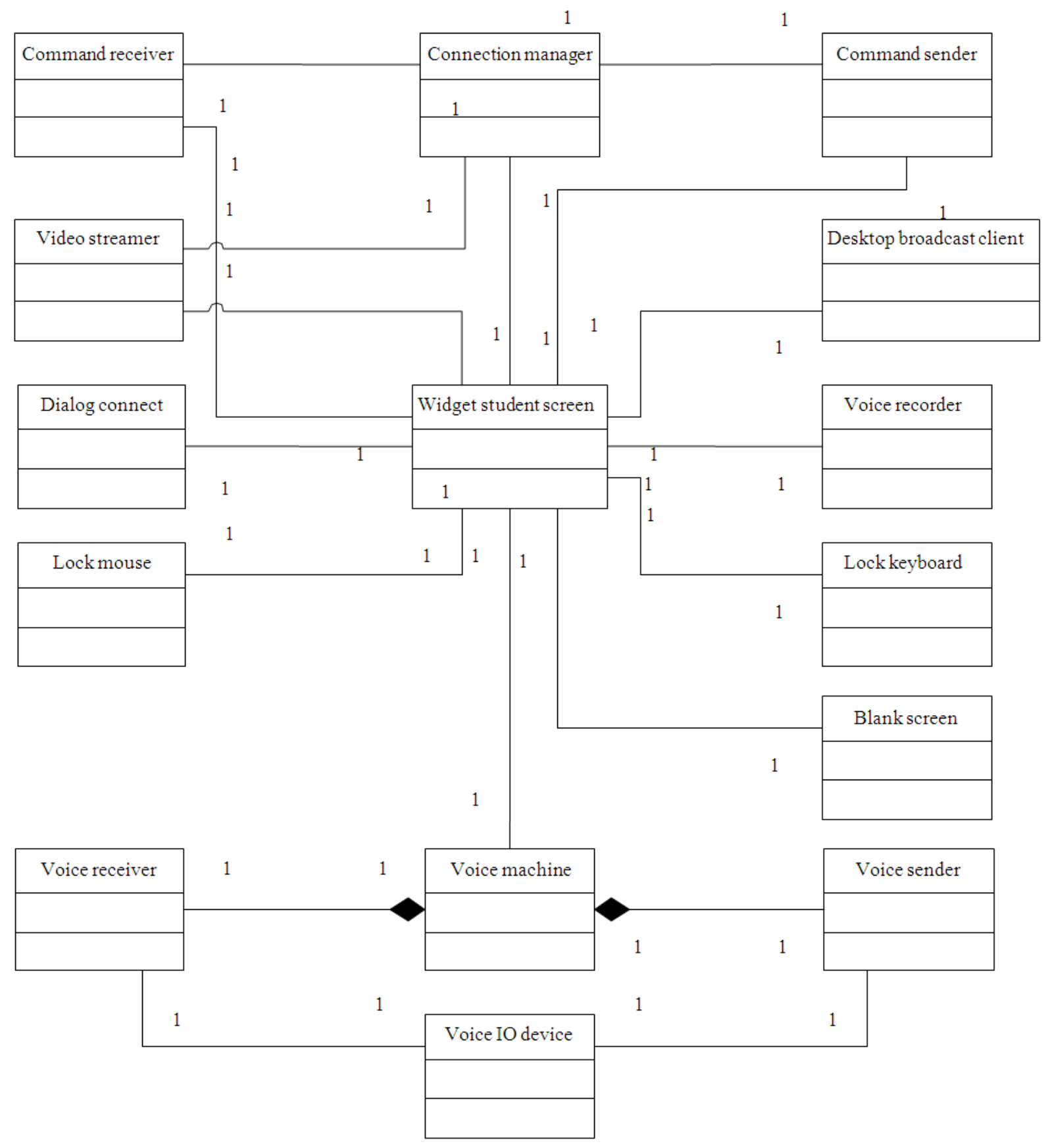

Fig. 10. Class diagram of the system (student application side)

The UDP connection is used for doing Speech and Share Desktop activity. This connection is very reliable for transferring data in high speed (Din et al., 2010). Last, the RTSP connection is used for Share Media activity.
The RTSP connection characteristics are similar to UDP connection, but much better. This connection is very suitable for sharing video and audio media that usually have big size (Suryadi et al., 2010). 


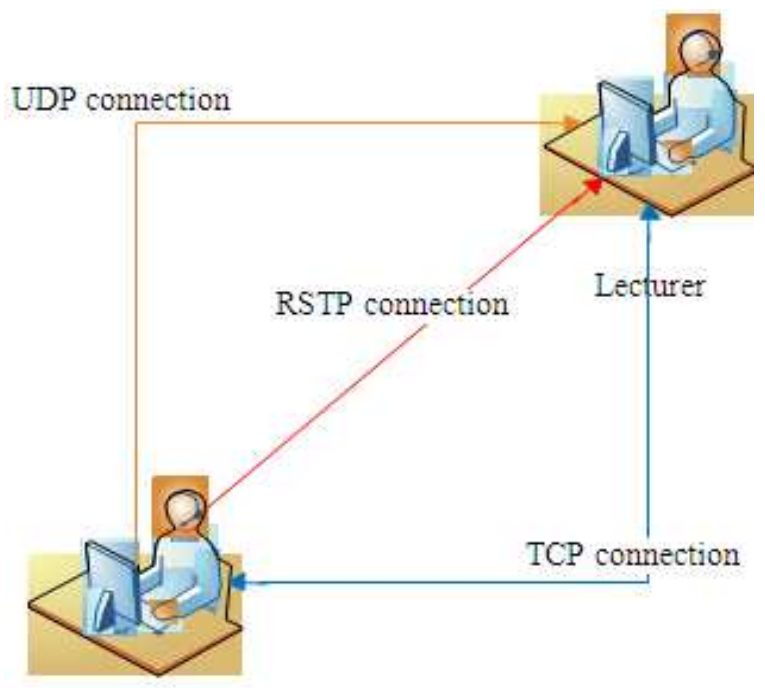

Student [1.N]

Fig. 11. Connection types that used in the system

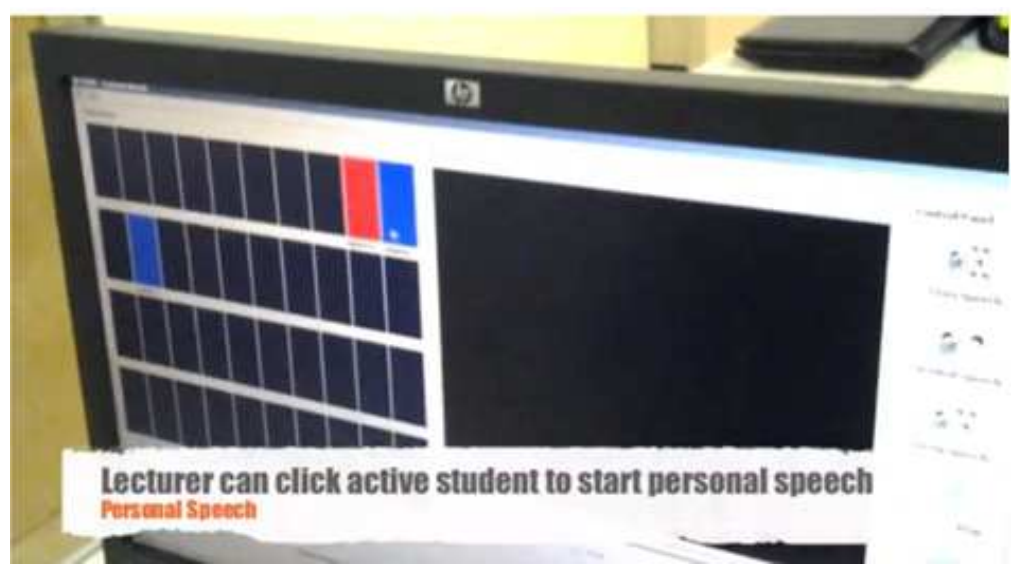

Fig. 12. Experiment session for personal speech activity

\subsection{Software}

For this research, we are using Windows operating system, Qt SDK and LibVLC library. The software/libraries below are a must:

- Operating System: Windows XP (all types)

- Qt SDK: MSVC version 4.8.0

- libgcc_s_dw2-1.dll

- mingwm10.dll

- QtCore4.dll

- QtGui4.dll

- QtMultimedia4.dll
- QtNetwork4.dll

- LibVLC Library : version 2.0

- plugin

- libvlc.dll

- libvlccore.dll

\subsection{Experimental Results}

Experiments of the application are done by doing technical and functional activity from Teacher's application and Student's application. Total of experiment activity are 54 activities. From 54 activities, 48 activities were successful. Other 6 activities are not yet developed. 
Table 1. Bandwidth consumption (in kbps)

\begin{tabular}{lcl}
\hline Packet & Average send & Average receive \\
\hline Audio & $5-12$ & $12-14$ \\
Audio and video & $20-26$ & $18-24$ \\
\hline
\end{tabular}

Bandwidth consumption for streaming audio is 12 kbps until 14 kbps. When the application streams audio and video, the bandwidth consumption increases about 18 kbps until 24 kbps Table 1.

Based on the experimental results, the system can run very well. The system has no obstacle in sharing video and audio data.

\section{CONCLUSION}

The system already tested in language classroom in Binus University. At the first version, the main functionality is only focusing on Class Speech, Personal Speech, Share Desktop and Share Video. All these functionality can run well, but for the next version needs several improvement. Features that can be added to the next version are integrated record speech with upload system, multi-way communication in group speech, additional activities for group speech such as share media and personal speech between two students, writing exam or practice and video conference (if needed).

\section{ACKNOWLEDGMENT}

This research funded by grant from Binus UniversityJakarta for the year 2012 .

\section{REFERENCES}

Din, I.U.D., S. Mahfooz and M. Adnan, 2010. Performance improvement of UDP and TCP traffic by CJM algorithm in voice transmission. Global J. Comput. Sci. Technol., 10: 19-23.

Eskicioglu, A.M. and D. Kopec, 2003. The ideal multimedia-enabled classroom: Perspectives from psychology, education and information science. J. Educ. Multimedia Hypermedia, 12: 199-221.

Lee, D.J., B.E. Carpenter and N. Brownlee, 2010. Media streaming observations: Trends in UDP to TCP ratio. Int. J. Adv. Syst. Measurem., 3: 147-162.

Sunardi, S., 2010. Multimedia pembelajaran tatasurya dengan pendekatan inkuiri bagi kelas X SMK. J. TeknologiInformasi, 6: 37-42.

Suryadi, S., A. IqbalSyamsu and H. ArieHendra, 2010. Video Streaming. H.263. melalui jaringan LAN. J. Elektronika, 10: 384-390.

Tayel, M.B. and A.A. Taha, 2008. Effect of TCP and UDP Parameters on the quality of Video streaming delivery over the internet. WSEAS Trans. Commun., 7: 653-662. 